\title{
Inequitable wages and tax evasion
}

Linda Dezső*1, James $\mathrm{Alm}^{2}$, and Erich Kirchler ${ }^{3}$

${ }^{1}$ Vienna Center for Experimental Economics, University of Vienna

${ }^{2}$ Department of Economics, Tulane University

${ }^{3}$ Department of Applied Psychology, University of Vienna

July 7,2020

Declarations of interest: none.

${ }^{*}$ Corresponding author. E-mail: linda.dezsoe@univie.ac.at. Postal addres: Oskar Morgenstern Platz 1, 5.313., 1190, Vienna, AT 


\begin{abstract}
In a two-stage, preregistered lab experiment (aspredcited.com \#36099), we examine whether wage inequity has a greater impact on tax compliance and on the beliefs about prevailing compliance norms among the wronged when it results from intentional human choice versus a random mechanism. Subjects are organized into groups of six. In the first stage, we perform a wage inequity manipulation by assigning equitable or inequitable wages to subjects as remuneration for a trivial, real-effort task. In the second stage, subjects are prompted to report their incomes, of which a certain percent is deducted but not redistributed between them. Next, subjects state their incentivized beliefs about the mean of the declared-to-true income ratio among their group members. We find that tax compliance and beliefs about the prevailing compliance norms are eroded when wage inequity stems from intentional human choice but not when the same wage is randomly chosen. Consequently, it is not the wage inequity per se that reduces tax compliance and corrupts beliefs about the norms, but rather the inequity due to human choice. Our results demonstrate that incidental unfairness in the form of intentional wage inequity adversely spills over onto tax compliance and beliefs about the prevailing compliance norms. In conclusion, intentional wage inequity can be harmful for the society as a whole.
\end{abstract}

Keywords: wage inequity; tax compliance; compliance norms; beliefs elicitation; lab experiment

JEL codes: H24; H26; D91; C91 


\section{Introduction}

A deliberately imposed injustice often leads to retaliation on the wrongdoer with the expectation of some loss repair at the wrongdoer's expense (Fehr \& Gächter, 2000; Greenberg, 1990) and, when lacking scope for reciprocity, it is likely to be followed by unethical behaviors if these increase the payoffs of the wronged (Houser, Vetter, \& Winter, 2012).

1 Indeed, growing research on (un)ethical behaviors documents that experiencing unfairness adversely shapes ethical preferences. After experiencing distributive injustice in the form of inequitable monetary outcomes, individuals are more likely to steal (Greenberg, 1993; John, Loewenstein, \& Rick, 2014), lie (Houser et al., 2012), or cheat (Birkelund \& Cherry, 2020; Galeotti, Kline, \& Orsini, 2017) to improve their financial condition. Furthermore, Grosch and Rau (2020) demonstrate that unfair payment schemes unleash antisocial behaviors among the wronged, even when these behaviors do not change their financial outcomes or lack any scope for retribution. These findings suggest that ethical preferences are susceptible to a prior episode of unfair treatment such that being wronged can erode ethics.

An undesirable implication of this malleability of ethical preferences is as follows: if individuals feel that they are or have been taken advantage of, they may be inclined to exploit situations where relaxing or adjusting ethics pays off (Elster, 1989). If so, the inequitable practices entrenching societies could have detrimental consequences on some institutions. Perhaps taxation is the most prominent example of these institutions. Tax

\footnotetext{
${ }^{1}$ In this paper, we follow Konow (2001) and use the terms (un)fairness, (in)justice, and (in)equity interchangeably.
} 
compliance is indispensable for providing public goods and assuring the operation of a welfare state, and although compliance is mandated by a centralized sanctioning scheme, ethics and social influence are still key components for securing sufficient compliance levels (e.g., Alm \& Torgler, 2011; Luttmer \& Singhal, 2014; Shleifer, 2004).

Indeed, there seems to be ample room for multilayered, nonpecuniary motivations to pay taxes, described under the umbrella term of "tax moral" (Luttmer \& Singhal, 2014). One component of the tax moral is an intrinsic ethical compass to which individuals prefer adhering and experience discomfort when deviating from it (Alm, 2019; Alm \& Torgler, 2011; Dwenger, Kleven, Rasul, \& Rincke, 2016). Another component, called conditional compliance, captures the individual motivations to adjust compliance to their beliefs about the prevailing compliance norms (Frey \& Torgler, 2007; Luttmer \& Singhal, 2014).

If the ethics and beliefs about the prevailing norms are essential for tax compliance, then the relationship between being wronged and a lapse in ethics may also manifest as decreased tax compliance. To address this conjecture, in a two-stage lab experiment, we examine whether wage inequity leads to decreased tax compliance and eroded beliefs about prevailing compliance norms and also estimate to what extent eroded beliefs explain the decreased compliance. Particularly, building on Houser et al. (2012), we determine if wage inequity has differential impacts on the subsequent tax compliance and perceived compliance norms when it is due to chance (i.e., randomness) versus deliberate human choice. This distinction allows us to estimate whether the reason for the underpayment systematically matters in shaping compliance levels and draw 
differential practical conclusions. If an intentionally imposed wage inequity matters, more focus could be put on monitoring employers' adherence to the collective or specific contracts prescribing certain wages or for legally assuring the existence and bargaining power of unions. If randomly caused inequity matters, the increased monitoring of tax compliance might be advisable in sectors where revenue heavily depends on random factors, such as weather conditions or other unforeseeable external causes.

As for the beliefs about prevailing compliance norms, we expect them to be susceptible to intentionally caused wage inequity but less so when the inequity is caused by a random event. Given the importance of conditional compliance, eroded beliefs can be precursors of decayed compliance in a society, which beliefs can then easily become self-fulfilling if observed compliance is indeed decayed. In other words, inequitable wage policies may also erode tax compliance in a society via the indirect channel of corrupting compliance norms.

In our experiment, we observed the lowest tax compliance and beliefs about compliance norms after a deliberately imposed wage inequity. Moreover, in all treatments, consistent with the notion of conditional compliance, we found a significant positive association between beliefs about prevailing compliance norms and compliance behavior. Additionally, one quarter of the decreased compliance upon intentional underpayment was mediated by the eroded beliefs, while the remainder was the direct effect of intentionally caused wage inequity. Finally, although beliefs about the compliance norms were lowest in the intentionally imposed inequity treatment, subjects were, on average, more likely to comply less than these already corrupted beliefs, whereas they were more 
likely to exceed their uncorrupted beliefs in the other three treatments. In sum, an intentionally imposed wage inequity corrupts the tax compliance and beliefs about compliance norms, while a randomly caused wage inequity does not affect tax compliance and beliefs.

The remainder of this paper is organized as follows. In section 2 , we review the related literature. Section 3 describes the experiment in detail, while section 4 presents the results. In section 5, we discuss results, identify potential limitations, and draw conclusions.

\section{Related literature}

The prominence of fairness concerns in a tax compliance choice has been identified in theoretical works (e.g., Bordignon, 1993; Schnellenbach, 2010) and examined systematically in empirical tax research (e.g., Barth, Cappelen, \& Ognedal, 2013; Bazart \& Bonein, 2014; Hofmann, Hoelzl, \& Kirchler, 2008; Spicer \& Becker, 1980). The common feature of these works is viewing taxpayers and the tax system as one unit in which the latter imposes some sort of (i.e., distributive or procedural) unfairness on the former, which reacts with decreased tax compliance.

In a laboratory experiment, Spicer and Becker (1980) demonstrate that subjects are more likely to evade taxes when they perceive the prevailing tax regime as treating them disadvantageously compared to others. In a similar vein, Kirchler, Hoelzl, and Wahl (2008) emphasize taxpayers' procedural fairness concerns by reporting increased tax 
evasion when taxpayers experience an unfair interaction with tax regime representatives. Furthermore, Fortin, Lacroix, and Villeval (2007) show that taxpayers are sensitive to horizontal inequity, such that they increase evasion when they learn that others with same income levels as theirs are assigned to a lower tax rate. Field studies report similar patterns. For example, Barth et al. (2013) find that Norwegian taxpayers increase tax evasion when they perceive that the tax system treats them unfairly and that evasion is supported by taxpayers' beliefs about being entitled to cheat.

Despite the abundance of research on how an unfair tax system affects tax compliance, to the best of our knowledge, no studies have hitherto examined whether tax compliance is susceptible to the incidental unfairness preceding a tax compliance choice. This is because the above studies focus on a reciprocal relationship, wherein the unfairness is imposed on taxpayers by the tax system. In real life, however, taxpayers may also be treated unfairly on the labor market by a form of wage inequity to which they may reciprocate, for instance, with decreased effort (Gächter \& Thöni, 2010). Nevertheless, in spite of the documented repercussions of unfair wage practices on employers, such as sabotage or various counterproductive behaviors, unfair wage practices still seem to flourish (Colquitt, Scott, Judge, \& Shaw, 2006; Williams, McDaniel, \& Nguyen, 2006).

We witness the media discourse and whistleblowing on the low-wage practices of thriving corporations (e.g., Leskin, 2018; Occhiogrosso, 2019; Thomas, 2018). In the popular media, the survival of these practices is mainly attributed to the dissolution of worker unions, which are often followed by loosening regulations on employer practices, raising the need for more efficient policies for enforcing equitable wages (Sainato, 2018). 
Academic research also identifies the detrimental consequences of wage inequity that emerge in starvation wages and eventually pierce into individual health (Woolf, Johnson, \& Geiger, 2006), educational prospects (Condron, 2011), interpersonal relationships (Dezső \& Loewenstein, 2012), and the financial conditions of the underpaid through payday loans (Stegman, 2007). Building on the research documenting that being wronged corrupts ethical preferences and the documented low-wage practices of some firms, we argue and empirically test that wage inequity might also adversely affect the entire society by eroding tax compliance.

From a standard standpoint, a tax compliance decision is a choice under risk in which the decision-maker maximizes the evasion gamble (Allingham \& Sandmo, 1972). Nevertheless, even Allingham and Sandmo (1972, p. 326.) acknowledged that their model is incapable of capturing all motives for tax compliance when claiming that the model is "...giving too little attention to non-pecuniary factors in taxpayers ...". Indeed, in real life as well as in tax experiments, we observe stunningly high levels of compliance, which requires identifying the factors influencing compliance choices and expanding the standard model (see, e.g., Alm (2019) for a recent and comprehensive review).

There are two candidate (and mutually nonexclusive) components accounting for the high compliance levels. The first factor is taxpayers' ethics, to which they wish to adhere (Alm \& Torgler, 2011), as a deviation from one's ethical standards could be costly due to image concerns (Mazar, Amir, \& Ariely, 2008; Ploner \& Regner, 2013). Similarly to how being wronged erodes ethical behavior when it is due to human choice but not due to randomness (Houser et al., 2012), we argue that tax compliance may also diversely 
decay from these two causes of wage inequity. Particular, when a wage inequity is due to a deliberate human choice, individuals would decrease their subsequent tax compliance. When, however, the same wage is due to a random event, tax compliance would be less affected.

The second important factor is the notion of conditional compliance - individuals' tendency to adjust their compliance to how much they believe or observe reference others are complying (Alm \& Torgler, 2011; Frey \& Torgler, 2007; Wenzel, 2005). A reference group could consist of anyone with whom the taxpayers share same traits or history (Bobek, Hageman, \& Kelliher, 2013). Experimental and field studies demonstrate the relationship between observed compliance norms and compliance behaviors. In a typical study, subjects play a multi-shot income reporting game and, depending on their treatment assignment, receive feedback on their group's compliance level from the previous round (Alm, Bloomquist, \& McKee, 2017; Fortin et al., 2007; Lefebvre, Pestieau, Riedl, \& Villeval, 2015). The overarching finding is that compliance increases when peers are observed to comply at a high versus low level. These laboratory findings are corroborated by the two large-scale field studies of Hallsworth, List, Metcalfe, and Vlaev (2017). The authors demonstrated that providing information about relevant others' compliance levels where the perceived proximity of the reference groups was exogenously varied, increases the tax compliance of real taxpayers. The closer taxpayers felt to those whose compliance levels were disclosed to them, the more likely they were to pay their tax dues timely.

While these experimental studies demonstrate the impact of perceived compliance 
norms on tax compliance, none of them elicited taxpayers' beliefs about the prevailing compliance norms or estimated the impact of these beliefs on compliance behavior. To estimate if the emerging beliefs are susceptible to wage inequity and if there is a differential influence of deliberately versus randomly caused wage inequities, we also elicit subjects' beliefs about the prevailing compliance norms in their groups. This enables us to test whether these beliefs erode after an inequitable treatment and estimate the extent by which they account for the decrease in observed compliance following an intentionally imposed wage inequity.

\section{The experiment}

We first describe the building blocks of the experiment and motivate our design choices. Then, we present the detailed procedure. See Appendix A for the complete experimental materials in the original language (with screenshots) and their English translation.

\subsection{The experimental framework}

The experiment unfolded in two stages. In stage one, we established the experimental manipulations by imposing equitable or inequitable wages as remunerations for completing a real-effort task where the realized wage was determined by a random process or an intentional human choice. In stage two, we elicited the two behaviors of interest: the tax compliance behavior (henceforth, compliance) in an income reporting task and subjects' incentivized beliefs (henceforth, beliefs) about the prevailing compliance norms among 
their peers. To mitigate the likelihood of subjects' home-grown tax compliance preferences and attitudes entering into our study, we used a neutral experimental language without any explicit references to taxes. Additionally, following the protocol of Hoffman, McCabe, and Smith (1996), subjects were truthfully informed that their identity was anonymous throughout the whole experiment not only among experimental subjects but also in the eyes of the experimental staff.

\subsubsection{Measuring risk preference}

To elicit risk preferences, we administered the Eckel and Grossman method (Eckel \& Grossman, 2002, 2008), henceforth EG task. The EG task is a simple method to elicit risk preferences wherein subjects are prompted to select one from a list of gambles that they would like to have played (Charness, Gneezy, \& Imas, 2013; Dave, Eckel, Johnson, \& Rojas, 2010). As in the original EG task design, the number of gambles could vary, we adapted the six-gamble version of Dave et al. (2010) to Hungarian Forints (HUF); see Table 1 for the gambles. ${ }^{2}$

Each of the six gambles included $50 \%$ chances of receiving either a high or a low payoff. In gambles 1 to 5, the expected returns increased linearly with risk. The expected return of gamble 6 was the same as that of gamble 5 , but had a higher standard deviation. The gambles were devised that more risk averse subjects would choose lower gamble numbers, while risk neutral and risk seeking subjects would choose higher gambles numbers, risk seekers tipically opting for gamble 6 .

\footnotetext{
${ }^{2}$ At the time of the experiment, 1 EUR $=334$ HUF.
} 


\subsubsection{Creating groups of six subjects}

For each experimental session, subjects were pooled into groups of six. One subject from each group was randomly assigned to the role of Type $B$, while the other five subjects were assigned to the role of Type $A$, and subjects were informed about their types. The fact and method (i.e., random mechanism) of this role assignment and the information that there are five Type A subjects and one Type B subject in each group were public knowledge.

\subsubsection{Assigning groups to Nature or Intent treatments}

Each group was assigned to one of the two levels of the first Mode factor, which determines how (i.e., via which method) the wage manipulation (i.e., second factor) was created. At the Intent level of the Mode factor, the Type B subject determined the wages for him/herself and for the five Type A group members. At the Nature level of the Mode factor, a random device determined the wages for both types.

\subsubsection{Establishing the wage inequity manipulation on the group level}

The wage inequity manipulation involved unmet wage entitlements, which approach builds on Konow (2001), Dezső and Loewenstein (2019), and Dezső, Loewenstein, Steinhart, Neszveda, and Szászi (2015). Konow (2001) reported that observers find wage differences unfair when workers performances are identical and there are no justifiable 
reasons for unequal wages. Similarly, across multiple experiments, Dezső and Loewenstein (2019) and Dezső et al. (2015) created asymmetric wage allocations between workers for identical performances with no reason for the wage differences. They found that the lower (i.e., inequitably) paid worker finds hes/her earnings unfair and claims compensation in a subsequent bargaining from the worker receiving the higher wage at his/her expense.

In our experiment, the received wage was the remuneration for completing the trivial task of labeling 10 simple images. Passing this image-labeling task required neither specific knowledge nor special spelling skills from the subjects, and has been previously used in other lab studies as a real-effort task (see, e.g., Dezső and Loewenstein (2019)). Although the task was trivial, by choosing to have subjects generate their income rather than endowing them, we aimed to create strong feelings of wage entitlement (Cherry, Frykblom, \& Shogren, 2002).

To exogenously set the wage entitlement, subjects were informed that anyone passing the minimum requirement of labeling any five images correctly was entitled to a wage of $3000 \mathrm{HUF}$ and that there are no performance rankings among subjects that could cause or justify wage differences between them. To implement the wage manipulation, despite the exogenously set wage entitlements, the wage each type received depended on which of the following two options was realized either by the deliberate choice of Type B subject as in the Intent treatment or due to a random device assigning equal probabilities to both outcomes as in the Nature treatment.

The two options were the following: 
1. Each Type A and B subject earned 3000 HUF for completing the image-labeling task.

2. Each Type A subject earns 1500 HUF, while the Type B subject earns 10500 HUF (i.e., 10 times the wage of Type A) for completing the image-labeling task.

If option 1 realized, Type $\mathrm{A}$ and $\mathrm{B}$ subjects received equitable and equal wages and the Wage factor was assigned to the Equitable factor level. If option 2 realized, the Wage factor was assigned to the Inequitable factor level, as Type A subjects received less than they were entitled to which also caused an inequality between As and Bs.

Another design choice was that information about the wage entitlements, actual wages, and method via which the realized wages were selected were disclosed prior to starting the image-labeling task. Consequently, when subjects started the task, they were all aware of their entitlements and the actual wages they would be receiving for successful task completion (i.e., whether their entitlements were met or not). Although this design choice may remove some of the strengths of the inequity manipulation and, in real life, wage inequity is more likely to emerge after the work is completed, we intended to eliminate any potential effects of surprise, resent, and rage in the Inequity treatments and relief and happiness in the Equity treatments. Nevertheless, in real life, the former two emotions may significantly shape behaviors after receiving an inequitable wage (e.g., Giacalone \& Greenberg, 1997). 


\subsubsection{Income reporting task}

In experimental tax research, there are three approaches for eliciting compliance behavior. In all of them, subjects are prompted to report their privately earned incomes of which a certain proportion is deducted and unpaid (i.e., tax), while facing some nonzero probability of being checked whether their income reports are truthful and, if not, pay a fine proportional to the evaded amount. The approaches differ in what happens to the pooled taxes.

In the so called "tax game", taxes are pooled and redistributed among group members, thus involving a strategic complexity in the compliance choice (e.g., Alm, Jackson, \& McKee, 1992). By contrast, in one version of the so called "income reporting task", the pooled taxes are simply kept by the experimenter, while in the other version, they are redistributed elsewhere (not among subjects whose taxes are pooled) and therefore, these versions eliminate strategic complexity from the choice. In our experiment, we implemented this latter version, and followed Fortin et al. (2007) and Coricelli, Joffily, Montmarquette, and Villeval (2010) in that the pooled taxes were paid into a scientific research fund which information was public knowledge. ${ }^{3}$ Additionally, to eliminate image concerns, subjects were assured that the fact of being checked on their reports, and that the outcome of this checkup would remain their private knowledge.

\footnotetext{
${ }^{3}$ We acknowledge that some subjects may still have perceived their contributions as public good payments even if the public good would only very remotely benefit them. Nevertheless, we have no reason to assume these perceptions would have systematically varied between conditions so as to have confounded our results.
} 


\subsubsection{Belief elicitation}

After the income reporting task, to estimate subjects' beliefs about their similarly treated peers' mean compliance, everyone estimated the mean declared and true income ratio among the Type A subjects in their groups. Type A subjects were instructed to exclude their own income reports from the estimation, and estimate the mean for the other four Type A group members. Type B subjects also estimated the mean declared and true income ratio for all five Type A subjects in their group. Both types knew that the estimation task was conducted under identical incentives for all subjects.

Building on Schlag, Tremewan, and Van der Weele (2015), estimates within a given range were monetary rewarded. Admittedly, there is an ongoing discussion about whether beliefs should be elicited before, after, or simultaneously to the focal behavior to ensure that beliefs and behaviors remain intact (i.e., they do not systematically influence each other). Nonetheless, d'Adda, Drouvelis, and Nosenzo (2016) demonstrated that, under proper incentives, beliefs and behaviors are uncontaminated and correspond to truthful preferences regardless of the elicitation order.

\subsection{Experimental procedure}

The approximately 20 - minute long experiment was programmed in oTree (Chen, Schonger, \& Wickens, 2016) and was conducted at the lab facilities of the Corvinus University of Budapest. There were no exclusion criteria for participation, as long as the subjects were adults (i.e., older than 18 years old). Subjects received a 500 HUF 
show - up fee, while any additional earnings depended on their luck and choices, of which they were truthfully informed. In each experimental session, subjects were pooled into groups of six. An average session included three groups, allowing us to randomize subjects into the different treatments. To facilitate the comprehension of the experimental procedure, Table 2 summarizes the experimental steps.

\section{Insert Table 2 here}

At the beginning of the experiment, subjects were organized into groups of six and each group was randomly assigned to the Intent or Nature treatments. Next, they read the instructions summarizing the forthcoming experimental steps and were provided information about the expected earnings, highlighting that these earnings depended on their choices and luck.

Next, everyone filled out a basic demographic survey and then completed the EG task whose oTree implementation was done using the oTree app of Holzmeister (2017), adapted to HUF. To avoid any wealth effects, the earnings from this task were only disclosed at the end of the experiment. Next, in each group, subjects learned that one subject was randomly assigned Type B, while the other five were Type A. They were assured that this type of assignment was anonymous (i.e., nobody, including the experimenters, knew who was Type A or B).

Next, they learned they were all to complete the same image-labeling task, entailing the labeling of 10 simple images. The completion criterion was correctly labeling any five images. Those meeting this criterion were entitled to a wage of 3000 HUF, while 
the others received no wage. At this point, we determined the wage they received for completing this task. In the Nature treatment, they all learned that a random mechanism is now selecting between two options, where each option was equally likely to be selected. In the Intent treatment, Type A subjects learned that the Type B subject is now selecting the actual wage from two options, while the Type B subject was in fact prompted to make his/her selection. Recall that option 1 involved 3000 HUF wage for both Types and option 2 involved a 1500 HUF wage for Type As and a 10500 HUF for Type B.

Next, all types in the Nature treatment learned which option was realized and hence, their actual wage was and the wage of the other type for completing the image-labeling task. Similarly, in the Intent treatment, Type A subjects learned which option Type B had selected and hence, the wages of both types for completing the image-labeling task.

In the next step, everyone responded to a four-item mid-survey. The first two items served as attention checks, testing whether subjects correctly remembered their actual wages, how they were determined, and how much their entitlements were. The second two questions asked them to rate their satisfaction with and, following Houser et al. (2012), the perceived fairness of their actual wages. Regardless of subjects' responses, they all proceeded to the image-labeling task.

Subsequently, all subjects completed the image-labeling task. After submitting their work, they received feedback on how many images they labeled correctly, whether they fulfilled the completion criteria of labeling at least five images correctly, the number of Type A subjects in their group fulfilling the completion criteria, and, only for Type A 
subjects, whether the Type B subject successfully completed the task. Moreover, they were reminded of their actual wage, how it was selected, and what was the actual wage of the Type B subject in their group.

In stage two (see the lower panel of Table 2), we prompted both subject types to report their earnings from the image-labeling task, both types knowing that everyone is reporting their incomes. Subjects were told that $25 \%$ of their reported income will be deducted and deposited in a scientific research fund. They were also told that they are all facing a $15 \%$ chance of having their income reports checked for whether the true amount was reported. If they were found to have under-reported, $50 \%$ of the unreported amount was deducted from their final earnings.

Next, we elicited subjects' beliefs about their peers' mean compliance. Particularly, we asked subjects to state their beliefs about the mean declared and true income ratio in their groups, expressed as a number between $0 \%$ and $100 \%$ on a slider, but only among Type A subjects and excluding themselves. They were informed that, if their estimates fell within a $10 \%$ range of the true mean, they would receive 500 HUF at the end of the experiment.

In the next step, subjects learned their experimental earnings (total and itemized). Then, they completed a four-item exit survey asking about: (1) how ethical an unbiased judge who knows their entire history would rate their income reporting behaviors; (2) how much they agree with the statement that it is fair to under-report if someone received less than the originally assigned entitlement; (3) how much they anchored their income reports on their beliefs about their other group members' reporting behaviors; 
and (4) how fair they found their experimental earnings.

The experiment concluded by paying the subjects in cash.

\section{Experimental design and predictions}

Crossing the Mode and Wage factors, we obtain a 2 X 2 factorial design with the following four treatments: Nature-Equity, Nature-Inequity, Intent-Equity, and Intent-Inequity.

Type B subjects were solely instrumental and, hence, we are uninterested in their behaviors. Consequently, our four predictions only pertain to the behaviors of Type A subjects. These predictions are as follows:

1. Beliefs would be lowest in the Intent-Inequity treatment.

2. Compliance would be lowest in the Intent-Inequity treatment.

3. In all four treatments, there would be a significant correlation between beliefs and compliance.

4. The observed decrease in compliance in the Intent-Inequity treatment would be to a significant level mediated by the decrease in beliefs.

\section{Results}

We enrolled 276 subjects into 46 experimental sessions, of which 23 sessions were assigned to the Nature and 23 to the Intent treatments. From the first row of the top panel of 
Table 3, we learn that sessions were unequally distributed between the four treatments. This is because the realization of the Wage factor depended on a random device in the Nature and on Type B subjects' choices in the Intent treatments. The second row presents how the total sample is distributed between treatments for both types. The third row shows how many Type A subjects we have in each treatment. The fourth row presents the final sample of 222 Type A subjects who passed the attention checks administered in the mid-survey. Note that the likelihood of not passing the attention checks does not differ across treatment groups, $\chi^{2}(3)=1.27$, n.s. Furthermore, all subjects completed the image-labeling task successfully. Finally, from the last row of the top panel of Table 3, we see that the mean experimental earnings of Type A subjects differ across the four treatments, $\mathrm{F}(3,218)=9.73, p \leq 0.001$, which is an obvious consequence of the Wage treatment manipulations.

\section{Insert Table 3 here}

As one can see from the lower panel of Table 3, neither mean age nor gender distribution differ between the four treatment groups. Across all treatments, the mean age is $21.23(2.03)$ years and $56.3 \%$ of subjects are male. Note that, although we had a three-level gender variable, no subjects indicated their gender as "other."

\subsection{Manipulation checks}

Recall that, after we implemented the experimental manipulations (i.e., assigned subjects to one of the four treatments), subjects responded to a four-item mid-survey. The 
responses to the first two items are used as attention-checks, and are instrumental in determining the final sample as presented in the fourth row of Table 3.

The two other items inquired about subjects' satisfaction and perceived fairness regarding their actual wage on the image-labeling task. We expected that, in the event of a successful manipulation, the means of the responses on these two items would be the lowest in the Intent-Inequity treatment. The results of regressing (OLS) the satisfaction and perceived fairness variables on the experimental factors and their interaction are summarized in Table 4 . In both models, we find a significant interaction term, confirming that the mean satisfaction and perceived fairness are lowest in the main experimental treatment.

\section{Insert Table 4 here}

\section{$5.2 \quad$ Testing predictions}

We have two key experimental variables. First, beliefs were entered as a percent, ranging between 0 and 100. Second, compliance is the ratio of the declared and true income. We re-scale both variables to range from 0 to 1 (all inclusive).

In Figure 1, we present the mean beliefs of the four treatments. We find that beliefs are lower in the Intent-Inequity than in Intent-Equity treatment, Mann-Whitney $\mathrm{U}=$ 1199.00, $p \leq 0.05$, and than in the Nature-Inequity treatment, Mann-Whitney $\mathrm{U}=$ $1199.50, p \leq 0.05$

Insert Figure 1 here 
To address our first prediction, we regressed (Tobit) beliefs on the experimental factors and their interaction and summarize the results in Table 5. Confirming our first prediction, beliefs are lowest in the Intent-Inequity treatment, while we find no main effects of Intent and Inequity.

\section{Insert Table 5 here}

Result 1: Beliefs about similarly treated peers' compliance are lowest in the IntentInequity treatment.

In Figure 2, we present the mean compliances in the four treatments. We find that compliance is lower in Intent-Inequity than in Intent-Equity, Mann-Whitney $\mathrm{U}=$ 1033.00, $p \leq 0.01$, and than in Nature-Inequity, Mann-Whitney $\mathrm{U}=834.00, p \leq 0.001$.

\section{Insert Figure 2 here}

To address our second and third predictions, we conduct a series of Tobit regressions under different specifications and summarize the results in Table 6. From the significant interaction term in Model I, we learn that the expected compliance level is lowest in the Intent-Inequity treatment when including only experimental factors and their interaction. In Model II, we add beliefs and find that their increase is associated with an increase in compliance levels, while we still obtain a significant Intent $\mathrm{X}$ Inequity interaction.

In Model III, we add gender (coded as a Male dummy) and risky choice. We determine the value for risky choice following Eckel and Grossman (2002) or Eckel and Grossman 
(2008). For each subject we take his/her gamble choice of the six offered gambles. A higher value on the risky choice is associated with lower risk aversion (i.e., higher risk seeking) and the means do not differ between the four treatment groups, the marginal mean (SD) being $3.32(1.25)$. Note that this marginal mean is roughly the same as reported in other studies using the six gambles version of the EG task (e.g., Dave et al., 2010). We see in Model III, that although we still obtain a marginally significant Intent $\mathrm{X}$ Inequity interaction and a positive association between beliefs and compliance, compliance is lower among males than females and a decrease in risk aversion is associated with a decrease in compliance.

\section{Insert Table 6 here}

Result 2: The compliance level is lowest in the Intent-Inequity treatment even after controlling for beliefs, gender, and risk preferences.

Result 3: There is a significant positive association between beliefs and compliance level.

\subsection{The relationship between beliefs and compliance}

We conduct a causal mediation analysis using a counterfactual-based method, according to Imai, Keele, and Tingley (2010) and Imai, Keele, and Yamamoto (2010), to determine whether and to what extent the effects of treatment manipulations on compliance are mediated by their effects on beliefs. The results show an average change of $\delta=-0.208$ in compliance from Nature-Inequity to Intent-Inequity due to the indirect effects of 
beliefs. This accounts for an estimated $\nu=24.957$ of the total (direct and indirect summed up) effects on mean compliance when changing from the Nature-Inequity to the Intent-Inequity treatment.

Result 4: Approximately one quarter of the decrease in compliance is observed in the Intent-Inequity treatment compared to the Nature-Inequity treatment is due to a decrease in beliefs, while the other three quarters is due to the direct effect of treatment manipulations.

Another way of looking at the beliefs and compliance relationship is comparing the two variables at the individual level using a series of Wilcoxon Signed-Ranks tests. ${ }^{4}$ We find that, in the Nature-Equity, Nature-Inequity, and Intent-Equity treatments, compliance is more likely to be higher than belief and Wilcoxon Signed-Rank tests' Zs are -3.304, -4.527 , and -1.868 , respectively, all being $p \leq 0.05$. At the same time, compliance is more likely to be lower than beliefs in the Intent-Inequity treatment, with Wilcoxon Signed-Ranks Z $=-2.197, p \leq 0.05$.

Result 5: In the Intent-Inequity treatment, subjects were more likely to comply below their beliefs, while they were more likely to comply above their beliefs in the other three treatments.

\subsection{Exit survey responses}

Finally, in Table 7, we summarize the exit survey responses. However, they should be interpreted with caution because subjects might have aimed to respond in a way that is

\footnotetext{
${ }^{4}$ Note that we did not preregister these comparisons.
} 
consistent with their experimental behaviors rather than providing true responses.

\section{Insert Table 7 here}

In the Judge row, we present the mean values for the question "How would an unbiased judge who knows how much money you earned on the image-labeling task and how your wage was determined judge your income reporting behavior?" We find no treatment differences, $\mathrm{W}(3,111)=0.374$, n.s.. ${ }^{5}$ Similarly, in the second row, we observe no treatment differences in subjects' agreement on "It is ethical to report less than the true income if A earned less on the image-labeling task than his/her entitlement", W(3, 113) $=1.433$, n.s.. In the third row, we present the mean responses to the question "To what extent did you anchor your income-reporting behavior on your beliefs about on how much your peers report?" and, again, we find no differences in treatment means, $\mathrm{F}(3,218)=0.843$, n.s.. Conversely, although not surprisingly, we find a treatment difference when it comes to evaluating the fairness of earnings, see the last row of Table 7. Regressing (OLS, overall model LR $\left.\chi^{2}(3)=82.74, p \leq 0.001\right)$ the perceived fairness of the earnings variable on the two experimental factors and their interaction, we find that Inequity decreases the mean reported fairness by an average of $0.91(0.18)$, Wald $\chi^{2}(1)$ $=23.11, p \leq 0.001$, and the fairness ratings are lower by $0.69(0.27)$ on average, Wald $\chi^{2}(1)=6.61, p \leq 0.01$ in the Intent-Inequity treatment. In other words, consistent with our expectations, subjects rated their earnings as least fair in the main experimental treatment.

\footnotetext{
${ }^{5}$ When necessary, we report the Welch statistics to account for unequal variances.
} 


\section{Discussion}

We manipulated the causes of inequitable wages and tested if receiving an inequitable wage adversely shapes tax compliance preferences and the beliefs about prevailing compliance norms. When the wage inequity arose due to a random process, subjects did not resort to increased tax evasion or to corrupting their beliefs about the prevailing compliance norms. By contrast, when the same wage inequity was due to a deliberate human choice, in which the decision-maker benefited at the expense of the wronged, tax compliance decreased and beliefs eroded. We found that effort levels did not differ across treatments, suggesting that an unfair wage and knowing in advance about paying taxes on the received wage did not cause an effort decrease in the real-effort task.

These divergent effects of the different causes of wage inequity suggest that it is not inequity per se or the corresponding failure of reaching an expected income level that deteriorates compliance. Instead, it matters whether inequity stems from an intentional human choice. The pattern of the results eliminates the alternative explanation that tax evasion is driven by failing to reach a target wage and corroborates Houser et al. (2012) in documenting that experiencing an intentionally imposed unfairness corrupts ethical preferences. These findings also confirm Elster (1989)'s warning regarding the spillover of incidental unfair treatments to behaviors that rely on subjective ethics. A practical consequence of these results is that resources allocated setting and enforcing equitable wages might pay off for the entire society, as they could mitigate the likelihood of compensation seeking by cheating the system. 
Unlike other papers investigating the relationship between being wronged and ethical preferences, where unethical behavior lacked expected monetary consequences, to mimic a tax compliance choice more closely, we applied a central sanctioning scheme. This design choice required us to control for risk preferences. We found a positive association between risk seeking and tax evasion consistent with, for instance, Coricelli et al. (2010), Bruner, D'Attoma, and Steinmo (2017), and Bernasconi and Bernhofer (2020) but in contrast to Dulleck et al. (2016).

Additionally, we observed eroded beliefs about the prevailing compliance norms among the intentionally wronged, which explained one quarter of the decreased compliance observed in this group. We argue that these results are worrisome for two reasons. First, it is worrying how swiftly individuals adjust their beliefs about the prevailing compliance norms after being wronged once. Perhaps, when individuals observe another person violating the implicit norm of fairness to their detriment, they infer that this behavior liberates everyone from the expectation of behaving ethically; almost as if there was a cross-norm inhibition in place (Keizer, Lindenberg, \& Steg, 2008). Second, the intimate relationship between beliefs and compliance uncovered in the mediation analysis indicates that conditional compliance emerges even in the laboratory (stripped of context), and people readily adjust their behaviors to these instantaneously formed corrupted beliefs. We suspect that this mechanism can easily give a fertile ground for a downward spiral and eventually, make inequitable wage practices costly for the entire society. 


\subsection{Limitations}

There are reasons for caution in interpreting our results. A common concern is whether laboratory experiments possess the necessary characteristics for external validity, given (among other features) their use of student subjects. However, we found evidence that the behavior of student subjects in laboratory experiments (including in tax compliance experiments) is not significantly different from that of non-student subjects, either in the laboratory or in similarly structured real-world settings (Alm, Bloomquist, \& McKee, 2015; Dai, Galeotti, \& Villeval, 2018). Additionally, our main result is detecting the qualitative treatment effects between being intentionally wronged versus by chance, thus adding to the literature on how being wronged shapes subsequent ethical preferences adversely (e.g., Grosch \& Rau, 2020; Houser et al., 2012).

Moreover, we adhered to a somewhat unusual experimental design by employing a one-shot income reporting game versus the more common multi-shot game in laboratory studies on tax compliance. However, in a multi-shot game, we believe that the wage inequity manipulation could have potentially dissipated. Additionally, by using a oneshot income reporting game, we eliminated the effect of dynamic learning, which could have systematically interacted both with compliance choices and belief formation.

\subsection{Concluding remarks}

Preferences for honest tax payments, although unarguably influenced by risk preferences, are malleable and depend on factors independent of the objective and perceived charac- 
teristics of a particular tax regime. In fact, tax compliance can be directly shaped by the wage allocation norms imposed on taxpayers and, beyond that, be indirectly affected by beliefs about compliance norms that are also susceptible to wage allocation norms. These arguments suggest that wage policy choices and their enforcement not only matter for individual wealth outcomes, but also have significant welfare implications and eventually determine the institutions a society creates. Consequently, the effects of inequitable wages we identified in this experiment are both important and concerning. They thus call for measures of promoting and enforcing equitable payments. Enforcing equitable payments, especially for those in vulnerable positions, should pay off not only at the individual level but also for the entire society.

\section{Acknowledgements}

Linda Dezső gratefully thanks funding from Herta Firnberg Fellowship (T-1047-G27) provided by the Austrian Research Fund. We would like to thank Jonathan Steinhart for his statistical advice and Alexander Wagner, Gergely Hajdú, Geoffrey Castillo and Christian Koch for their helpful comments on the experimental design and on the manuscript. We are immensely grateful to Dániel B. Kalotai, Lőrinc Szánthó and Márton Budai for providing excellent research assistance. Additionally, we thank Judit Maros for editing the text of the Hungarian experimental instructions. 


\section{References}

Allingham, M. G., \& Sandmo, A. (1972). Income tax evasion: A theoretical analysis. Journal of Public Economics, 1(3-4), 323-338.

Alm, J. (2019). What motivates tax compliance? Journal of Economic Surveys, 33(2), 353-388. doi: 10.1111/joes.12272

Alm, J., Bloomquist, K. M., \& McKee, M. (2015). On the external validity of laboratory tax compliance experiments. Economic Inquiry, 53(2), 1170-1186. doi: doi.org/ 10.1111/ecin. 12196

Alm, J., Bloomquist, K. M., \& McKee, M. (2017). When you know your neighbour pays taxes: Information, peer effects and tax compliance. Fiscal Studies, 38(4), 587-613. doi: 10.1111/1475-5890.12111

Alm, J., Jackson, B., \& McKee, M. (1992). Institutional uncertainty and taxpayer compliance. The American Economic Review, 82(4), 1018-1026. doi: www.jstor .org/stable/2117358

Alm, J., \& Torgler, B. (2011). Do ethics matter? tax compliance and morality. Journal of Business Ethics, 101(4), 635-651. doi: 10.1007/s10551-011-0761-9

Barth, E., Cappelen, A. W., \& Ognedal, T. (2013). Fair tax evasion. Nordic Journal of Political Economy(38), 1-16.

Bazart, C., \& Bonein, A. (2014). Reciprocal relationships in tax compliance decisions. Journal of Economic Psychology, 40, 83-102. doi: 10.1016/j.joep.2012.10.002

Bernasconi, M., \& Bernhofer, J. (2020). Catch me if you can: Testing the reduction of compound lotteries axiom in a tax compliance experiment. Journal of Behavioral 
and Experimental Economics, 84, 101479. doi: 10.1016/j.socec.2019.101479

Birkelund, J., \& Cherry, T. L. (2020). Institutional inequality and individual preferences for honesty and generosity. Journal of Economic Behavior $\&$ Organization. doi: 10.1016/j.jebo.2019.12.014

Bobek, D. D., Hageman, A. M., \& Kelliher, C. F. (2013). Analyzing the role of social norms in tax compliance behavior. Journal of Business Ethics, 115(3), 451-468. doi: $10.1007 /$ s10551-012-1390-7

Bordignon, M. (1993). A fairness approach to income tax evasion. Journal of Public Economics, 52(3), 345-362. doi: 10.1016/0047-2727(93)90039-V

Bruner, D. M., D'Attoma, J., \& Steinmo, S. (2017). The role of gender in the provision of public goods through tax compliance. Journal of Behavioral and Experimental Economics, 71, 45-55. doi: 10.1016/j.socec.2017.09.001

Charness, G., Gneezy, U., \& Imas, A. (2013). Experimental methods: Eliciting risk preferences. Journal of Economic Behavior \& Organization, 87, 43-51. doi: 10 $.1016 / j . j e b o .2012 .12 .023$

Chen, D. L., Schonger, M., \& Wickens, C. (2016). otree - an open-source platform for laboratory, online, and field experiments. Journal of Behavioral and Experimental Finance, 9, 88-97. doi: 10.1016/j.jbef.2015.12.001

Cherry, T. L., Frykblom, P., \& Shogren, J. F. (2002). Hardnose the dictator. American Economic Review, 92(4), 1218-1221. doi: www.jstor.org/stable/3083309

Colquitt, J. A., Scott, B. A., Judge, T. A., \& Shaw, J. C. (2006). Justice and personality: Using integrative theories to derive moderators of justice effects. Organizational Behavior and Human Decision Processes, 100(1), 110-127. doi: 10.1016/j.obhdp 
.2005 .09 .001

Condron, D. J. (2011). Egalitarianism and educational excellence: Compatible goals for affluent societies? Educational Researcher, 40(2), 47-55. doi: 10.3102/ 0013189X11401021

Coricelli, G., Joffily, M., Montmarquette, C., \& Villeval, M. C. (2010). Cheating, emotions, and rationality: an experiment on tax evasion. Experimental Economics, 13(2), 226-247. doi: 10.1007/s10683-010-9237-5

d'Adda, G., Drouvelis, M., \& Nosenzo, D. (2016). Norm elicitation in within-subject designs: Testing for order effects. Journal of Behavioral and Experimental Economics, 62, 1-7. doi: 10.1016/j.socec.2016.02.003

Dai, Z., Galeotti, F., \& Villeval, M. C. (2018). Cheating in the lab predicts fraud in the field: An experiment in public transportation. Management Science, 64(3), 1081-1100. doi: 10.1287/mnsc.2016.2616

Dave, C., Eckel, C. C., Johnson, C. A., \& Rojas, C. (2010). Eliciting risk preferences: When is simple better? Journal of Risk and Uncertainty, 41(3), 219-243. doi: $10.1007 / \mathrm{s} 11166-010-9103-\mathrm{Z}$

Dezső, L., \& Loewenstein, G. (2012). Lenders' blind trust and borrowers' blind spots: A descriptive investigation of personal loans. Journal of Economic Psychology, 33(5), 996-1011. doi: 10.1016/j.joep.2012.06.002

Dezső, L., \& Loewenstein, G. (2019). Self-serving invocations of shared and asymmetric history in negotiations. European Economic Review, 120, 103309. doi: 10.1016/ j.euroecorev.2019.103309

Dezső, L., Loewenstein, G., Steinhart, J., Neszveda, G., \& Szászi, B. (2015). The per- 
nicious role of asymmetric history in negotiations. Journal of Economic Behavior E) Organization, 116, 430-438. doi: 10.1016/j.jebo.2015.05.016

Dulleck, U., Fooken, J., Newton, C., Ristl, A., Schaffner, M., \& Torgler, B. (2016). Tax compliance and psychic costs: behavioral experimental evidence using a physiological marker. Journal of Public Economics, 134, 9-18. doi: 10.1016/ j.jpubeco.2015.12.007

Dwenger, N., Kleven, H., Rasul, I., \& Rincke, J. (2016). Extrinsic and intrinsic motivations for tax compliance: Evidence from a field experiment in germany. American Economic Journal: Economic Policy, 8(3), 203-32. doi: 10.1257/pol.20150083

Eckel, C. C., \& Grossman, P. J. (2002). Sex differences and statistical stereotyping in attitudes toward financial risk. Evolution and Human Behavior, 23(4), 281-295. doi: 10.1016/S1090-5138(02)00097-1

Eckel, C. C., \& Grossman, P. J. (2008). Forecasting risk attitudes: An experimental study using actual and forecast gamble choices. Journal of Economic Behavior \& Organization, 68(1), 1-17. doi: 10.1016/j.jebo.2008.04.006

Elster, J. (1989). Solomonic judgements: Studies in the limitation of rationality. Cambridge University Press.

Fehr, E., \& Gächter, S. (2000). Fairness and retaliation: The economics of reciprocity. Journal of Economic Perspectives, 14(3), 159-181. doi: 10.1257/jep.14.3.159

Fortin, B., Lacroix, G., \& Villeval, M.-C. (2007). Tax evasion and social interactions. Journal of Public Economics, 91(11-12), 2089-2112. doi: 10.1016/j.jpubeco.2007 .03 .005

Frey, B. S., \& Torgler, B. (2007). Tax morale and conditional cooperation. Journal of 
Comparative Economics, 35(1), 136-159. doi: 10.1016/j.jce.2006.10.006

Gächter, S., \& Thöni, C. (2010). Social comparison and performance: Experimental evidence on the fair wage-effort hypothesis. Journal of Economic Behavior \& Organization, 76(3), 531-543. doi: 10.1016/j.jebo.2010.08.008

Galeotti, F., Kline, R., \& Orsini, R. (2017). When foul play seems fair: Exploring the link between just deserts and honesty. Journal of Economic Behavior $\&$ Organization, 142, 451-467. doi: 10.1016/j.jebo.2017.08.007

Giacalone, R. A., \& Greenberg, J. (1997). Antisocial behavior in organizations. Sage.

Greenberg, J. (1990). Employee theft as a reaction to underpayment inequity: The hidden cost of pay cuts. Journal of Applied Psychology, 75(5), 561-568. doi: $10.1037 / 0021-9010.75 .5 .561$

Greenberg, J. (1993). Stealing in the name of justice: Informational and interpersonal moderators of theft reactions to underpayment inequity. Organizational Behavior and Human Decision Processes, 54(1), 81-103. doi: 10.1006/obhd.1993.1004

Grosch, K., \& Rau, H. A. (2020). Procedural unfair wage differentials and their effects on unethical behavior. Economic Inquiry. doi: /10.1111/ecin.12906

Hallsworth, M., List, J. A., Metcalfe, R. D., \& Vlaev, I. (2017). The behavioralist as tax collector: Using natural field experiments to enhance tax compliance. Journal of Public Economics, 148, 14-31. doi: 10.1016/j.jpubeco.2017.02.003

Hoffman, E., McCabe, K., \& Smith, V. L. (1996). Social distance and other-regarding behavior in dictator games. American Economic Review, 86(3), 653-660. doi: www.jstor.org/stable/2118218

Hofmann, E., Hoelzl, E., \& Kirchler, E. (2008). Preconditions of voluntary tax com- 
pliance: Knowledge and evaluation of taxation, norms, fairness, and motivation to cooperate. Zeitschrift für Psychologie/Journal of Psychology, 216(4), 209-217. doi: $10.1027 / 0044-3409.216 .4 .209$

Holzmeister, F. (2017). oTree: Ready-made apps for risk preference elicitation methods. Journal of Behavioral and Experimental Finance, 16, 33-38. doi: 10.1016/j.jbef .2017 .08 .003

Houser, D., Vetter, S., \& Winter, J. (2012). Fairness and cheating. European Economic Review, 56 (8), 1645-1655. doi: doi.org/10.1016/j.euroecorev.2012.08.001

Imai, K., Keele, L., \& Tingley, D. (2010). A general approach to causal mediation analysis. Psychological Methods, 15(4), 309. doi: 10.1037/a0020761

Imai, K., Keele, L., \& Yamamoto, T. (2010). Identification, inference and sensitivity analysis for causal mediation effects. Statistical science, 51-71. doi: www.jstor.org/ stable/41058997

John, L. K., Loewenstein, G., \& Rick, S. I. (2014). Cheating more for less: Upward social comparisons motivate the poorly compensated to cheat. Organizational Behavior and Human Decision Processes, 123(2), 101-109. doi: doi.org/10.1016/ j.obhdp.2013.08.002

Keizer, K., Lindenberg, S., \& Steg, L. (2008). The spreading of disorder. Science, 322(5908), 1681-1685. doi: 10.1126/science.1161405

Kirchler, E., Hoelzl, E., \& Wahl, I. (2008). Enforced versus voluntary tax compliance: The "slippery slope" framework. Journal of Economic Psychology, 29(2), 210-225. doi: 10.1016/j.joep.2007.05.004

Konow, J. (2001). Fair and square: the four sides of distributive justice. Journal of 
Economic Behavior $\&$ Organization, 46(2), 137-164. doi: 10.1016/S0167-2681(01) 00194-9

Lefebvre, M., Pestieau, P., Riedl, A., \& Villeval, M. C. (2015). Tax evasion and social information: an experiment in belgium, france, and the netherlands. International Tax and Public Finance, 22(3), 401-425. doi: 10.1007/s10797-014-9318-z

Leskin, P. (2018). Amazon says it 'listened to our critics' as it raised its minimum wage to $\$ 15$ - here's how the clash between Bernie Sanders and Jeff Bezos went down. Business Insider. Retrieved from https://www . businessinsider.com/amazon-minimum-wage-timeline-coming -under-fire-pay-workers-2018-10?r=DE\{\\&\}IR=T

Luttmer, E. F., \& Singhal, M. (2014). Tax morale. Journal of Economic Perspectives, 28(4), 149-68. doi: 10.1257/jep.28.4.149

Mazar, N., Amir, O., \& Ariely, D. (2008). The dishonesty of honest people: A theory of self-concept maintenance. Journal of Marketing Research, 45(6), 633-644. doi: $10.1509 / j m k r .45 .6 .633$

Occhiogrosso, G. (2019, apr). McDonald's Abandons Its Fight Against \$15 Minimum Wage. Forbes. Retrieved from https://www.forbes.com/sites/ garyocchiogrosso/2019/04/04/mcdonalds-abandons-its-fight-against-15 -minimum-wage/\{\\#\}a614cf6659f 1

Ploner, M., \& Regner, T. (2013). Self-image and moral balancing: An experimental analysis. Journal of Economic Behavior \& Organization, 93, 374-383. doi: 10 $.1016 / j . j e b o .2013 .03 .030$

Sainato, M. (2018, July). Exploited Amazon workers need a union. When will they 
get one? The Guardian. Retrieved from https://www.theguardian.com/ commentisfree/2018/jul/08/amazon-jeff-bezos-unionize-working -conditions

Schlag, K. H., Tremewan, J., \& Van der Weele, J. J. (2015). A penny for your thoughts: a survey of methods for eliciting beliefs. Experimental Economics, 18(3), 457-490. doi: $10.1007 / \mathrm{s} 10683-014-9416-\mathrm{x}$

Schnellenbach, J. (2010). Vertical and horizontal reciprocity in a theory of taxpayer compliance. In Developing alternative frameworks explaining tax compliance (pp. 56-73). Routlidge, London.

Shleifer, A. (2004). Does competition destroy ethical behavior? American Economic Review, 94(2), 414-418.

Spicer, M. W., \& Becker, L. A. (1980). Fiscal inequity and tax evasion: An experimental approach. National Tax Journal, 171-175. doi: www.jstor.org/stable/41862299

Stegman, M. A. (2007). Payday lending. Journal of Economic Perspectives, 21(1), 169-190. doi: 10.1257/jep.21.1.169

Thomas, L. (2018, oct). Amazon's minimum wage hike puts the pressure on Walmart, Target and others to follow. CNBC. Retrieved from https://www.cnbc.com/2018/10/02/amazons-minimum-wage-hike-puts -pressure-on-walmart-target-to-follow.html

Wenzel, M. (2005). Motivation or rationalisation? causal relations between ethics, norms and tax compliance. Journal of Economic Psychology, 26(4), 491-508. doi: 10.1016/j.joep.2004.03.003

Williams, M. L., McDaniel, M. A., \& Nguyen, N. T. (2006). A meta-analysis of the 
antecedents and consequences of pay level satisfaction. Journal of Applied Psychology, 91 (2), 392. doi: 10.1037/0021-9010.91.2.392

Woolf, S. H., Johnson, R. E., \& Geiger, H. J. (2006). The rising prevalence of severe poverty in america: a growing threat to public health. American Journal of Preventive Medicine, 31(4), 332-341. doi: 10.1016/j.amepre.2006.06.022 


\section{FIGURES}

Figure 1: Mean beliefs in the four treatments

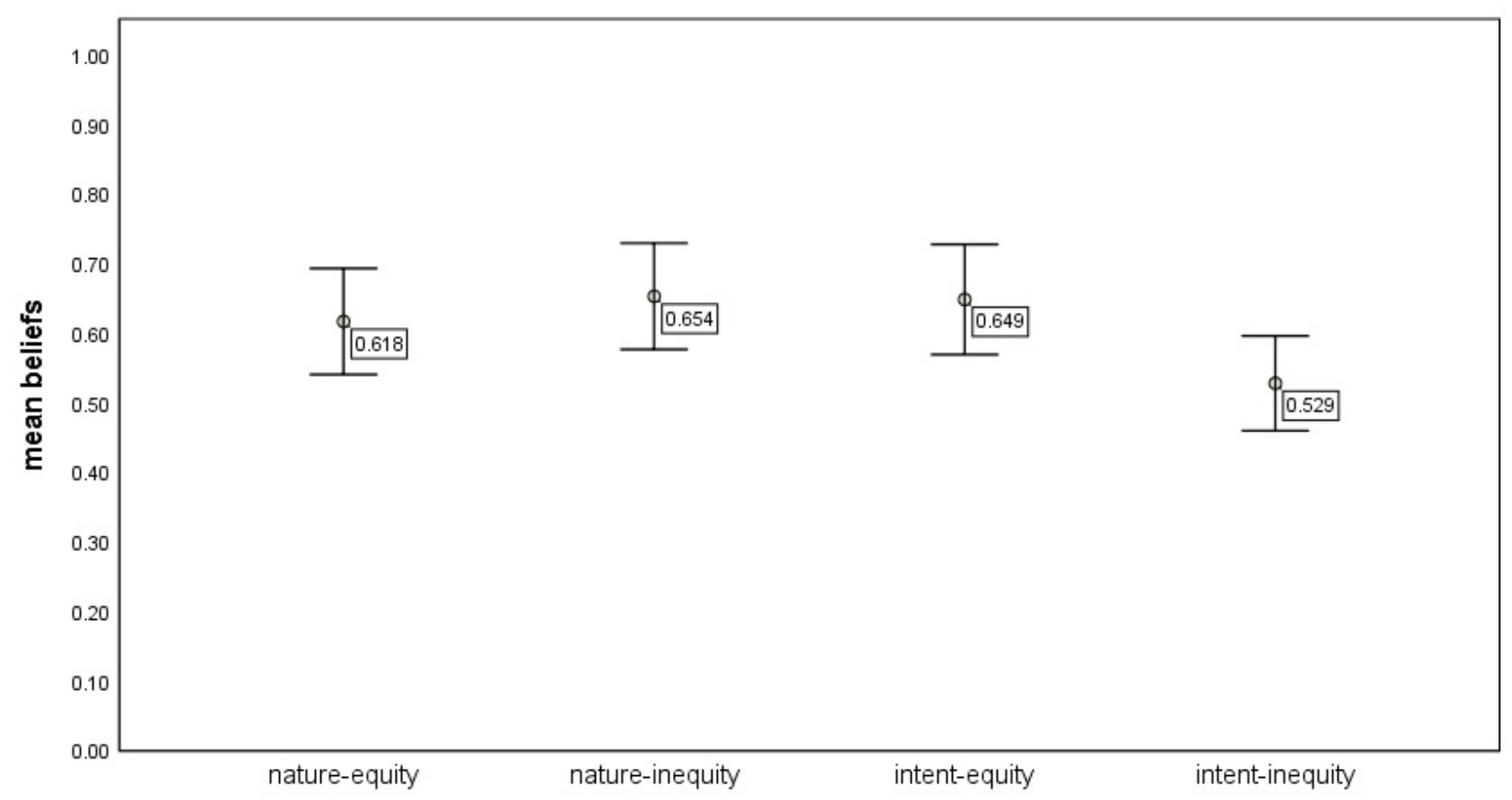

Notes: Mean beliefs are presented for each treatment. The error bars represent $95 \%$ CIs. 
Figure 2: Mean compliance in the four treatments

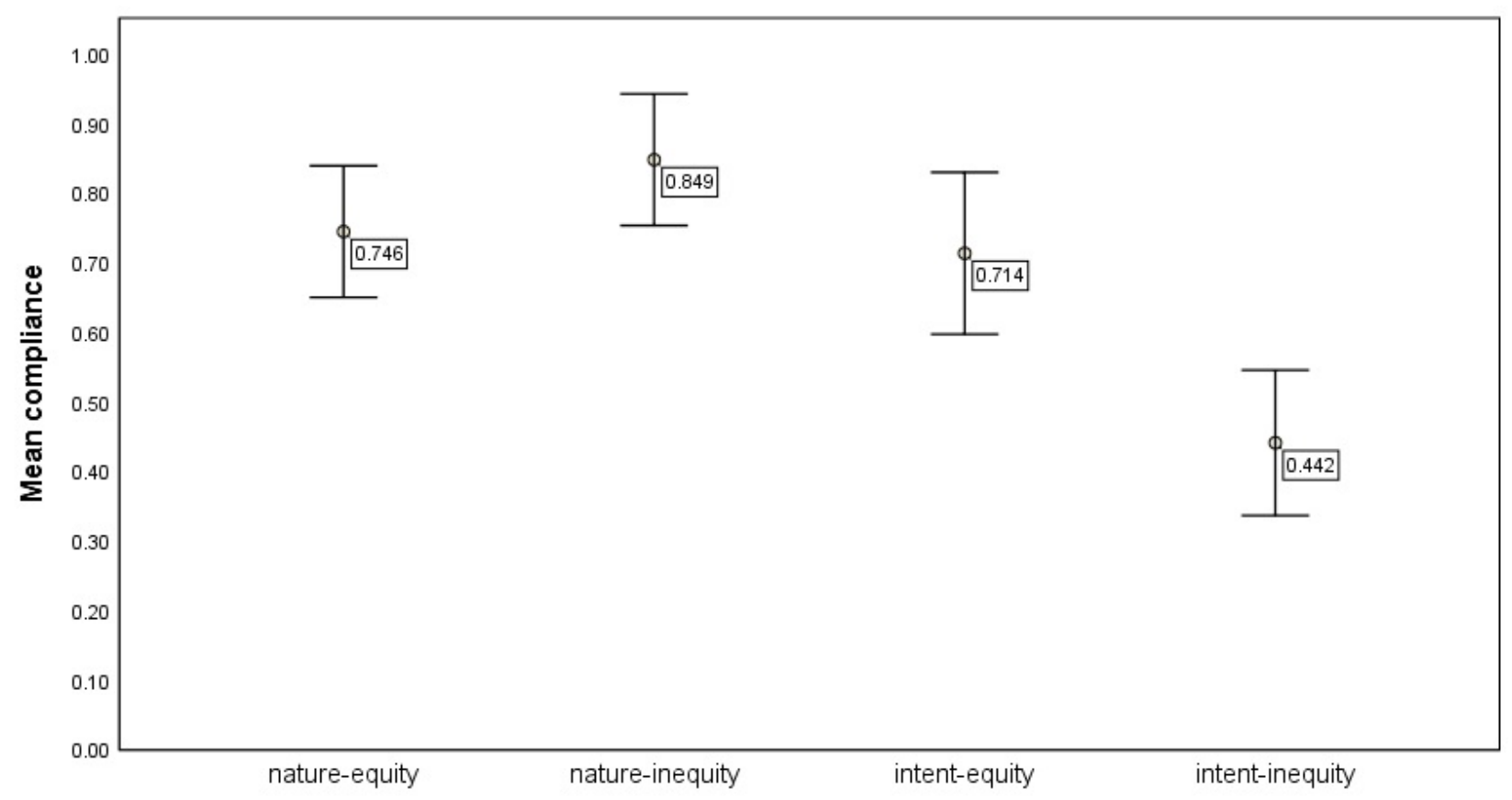

Notes: Mean compliance is presented for each treatment. The error bars represent $95 \%$ CIs. 
TABLES

Table 1. Lotteries in the EG task adapted to Hungarian Forints (HUF)

\begin{tabular}{llllllll}
\hline \hline Gamble & Low payoff & Likelihood & High payoff & Likelihood & Expected return & Standard deviation & Implied CRRA range \\
\hline Gamble 1 & $2000 \mathrm{HUF}$ & $50 \%$ & $2000 \mathrm{HUF}$ & $50 \%$ & $2000 \mathrm{HUF}$ & 0 & $3.74<r$ \\
Gamble 2 & $1700 \mathrm{HUF}$ & $50 \%$ & $2700 \mathrm{HUF}$ & $50 \%$ & $2200 \mathrm{HUF}$ & 500 & $1.25<r<3.74$ \\
Gamble 3 & $1400 \mathrm{HUF}$ & $50 \%$ & $3400 \mathrm{HUF}$ & $50 \%$ & $2400 \mathrm{HUF}$ & 1000 & $0.77<r<1.25$ \\
Gamble 4 & $1100 \mathrm{HUF}$ & $50 \%$ & $4100 \mathrm{HUF}$ & $50 \%$ & $2600 \mathrm{HUF}$ & 1500 & $0.55<r<0.77$ \\
Gamble 5 & $800 \mathrm{HUF}$ & $50 \%$ & $4800 \mathrm{HUF}$ & $50 \%$ & $2800 \mathrm{HUF}$ & 2000 & $0<r<0.55$ \\
Gamble 6 & $100 \mathrm{HUF}$ & $50 \%$ & $5500 \mathrm{HUF}$ & $50 \%$ & $2800 \mathrm{HUF}$ & 1700 & $R<0$ \\
\hline \hline
\end{tabular}

Note: CRRA is the constant relative risk aversion. 
Table 2. Summary of the experimental steps

\section{Stage 1}

1. Pooling subjects into groups of six and randomly assigning them to the Nature or Intent treatments.

2. Describing the experimental steps and information on the expected experimental earnings.

3. Demographic questions.

4. $\quad$ EG task - eliciting risk preferences.

5. Type assignment: one Type B and five Type As per group.

6. Creating the wage manipulation.

7. Four-item mid-survey.

8. Image-labeling task.

9. Information about successful task completion, reminder about the actual wage, and how it was selected.

\section{Stage 2}

10. Income reporting instructions and details.

11. Income reporting.

12. Estimating mean group compliance.

13. Learning about experimental earnings (total and itemized).

14. Exit survey. 
Table 3. Summary of the sample

\begin{tabular}{|c|c|c|c|c|}
\hline & \multicolumn{2}{|c|}{ Nature } & \multicolumn{2}{|c|}{ Intent } \\
\hline & Equity & Inequity & Equity & Inequity \\
\hline Number of conducted sessions & 13 & 10 & 9 & 14 \\
\hline $\mathrm{N}$ Types $\mathrm{A}$ and $\mathrm{B}$ & 78 & 60 & 54 & 84 \\
\hline N Type A & 65 & 50 & 45 & 70 \\
\hline Final N Type A & 63 & 47 & 44 & 68 \\
\hline Mean (SD) earnings in HUF & $5434.52(1310.07)$ & $4222.06(1242.11)$ & $5302.84(1614.81)$ & $4476.94(1484.37)$ \\
\hline Mean (SD) age in years & $21.29(1.93)^{1}$ & $20.98(1.58)$ & $20.84(1.74)$ & $21.59(2.49)$ \\
\hline Male N (\%) & $41(65.1 \%)$ & $24(51.1 \%)$ & $21(47.7 \%)$ & $39(57.4 \%)$ \\
\hline
\end{tabular}

Notes: ${ }^{1}$ Two subjects were excluded as they indicated the birth year to be 1900 . 
Table 4. Summary of OLS regressions of satisfaction with and perceived fairness of the image-labeling task earnings on experimental factors and their interaction

\begin{tabular}{lll}
\hline \hline & Satisfaction & Perceived fairness \\
\hline Intercept & $0.619(0.113)^{* * *}$ & $0.921(0.113)^{* * *}$ \\
Intent & $0.290(0.176)^{+}$ & $0.148(0.177)$ \\
Inequity & $-0.981(0.173)^{* * *}$ & $-0.984(0.173)^{* * *}$ \\
Intent X Inequity & $-0.605(0.245)^{* *}$ & $-0.584(0.245)^{*}$ \\
\hline LR $\chi^{2}$ & $96.16^{* * *}$ & $98.41^{* * *}$ \\
Df & 3 & 3 \\
$\mathrm{~N}$ & 222 & 222 \\
\hline \hline
\end{tabular}

Notes: Standard errors are in parentheses.

${ }^{* * *} p \leq 0.001,{ }^{* *} p \leq 0.01,{ }^{*} p \leq 0.05,{ }^{+} p \leq 0.10$ 
Table 5. Summary of Tobit regression

results of beliefs on experimental factors

and their interaction

Beliefs

\begin{tabular}{ll}
\hline Intercept & $0.629(0.038)^{* * *}$ \\
Intent & $0.017(0.059)$ \\
Inequity & $0.025(0.057)$ \\
Intent X Inequity & $-0.140(0.082)^{+}$ \\
\hline Log-Likelihood & -61.46 \\
LL $\chi^{2}$ & $6.51+$ \\
Df & 3 \\
$\mathrm{~N}$ & 222 \\
\hline \hline
\end{tabular}

Notes: Standard errors are in parentheses.

${ }^{* * *} p \leq 0.001,{ }^{+} p \leq 0.10$ 
Table 6. Summary of Tobit regressions results of compliance with different model specifications

\begin{tabular}{llll}
\hline \hline & \multicolumn{1}{c}{ Model I } & Model II & \multicolumn{1}{c}{ Model III } \\
\hline Intercept & $1.223(0.149)^{* * *}$ & $-0.099(0.166)$ & $0.665(0.29)^{* *}$ \\
Intent & $-0.139(0.224)$ & $-0.242(0.174)$ & $-0.242(0.171)$ \\
Inequity & $0.318(0.233)$ & $0.205(0.184)$ & $0.037(0.176)$ \\
Intent X Inequity & $-0.938(0.318)^{* *}$ & $-0.540(0.249)^{*}$ & $-0.407(0.237)^{+}$ \\
Beliefs & & $2.081(0.221)^{* * *}$ & $1.953(0.211)^{* * *}$ \\
Male & & & $-0.354(0.120)^{* *}$ \\
Risky choice & & -167.34 & $-0.127(0.048)^{* *}$ \\
\hline Log-Likelihood & -209.46 & $111.82^{* * *}$ & $131.47^{* * *}$ \\
LL $\chi^{2}$ & $27.58^{* * *}$ & 4 & 6 \\
Df & 3 & 222 & 222 \\
\hline \hline
\end{tabular}

Notes: Standard errors are in parentheses.

${ }^{* * *} p \leq 0.001,{ }^{* *} p \leq 0.01,{ }^{*} p \leq 0.05,{ }^{+} p \leq 0.10$ 
Table 7. Means and standard deviations of the exit survey responses in the four treatment groups and statistical tests of differences between the groups

\begin{tabular}{lcccc}
\hline \hline & \multicolumn{2}{c}{ Nature } & \multicolumn{2}{c}{ Intent } \\
\cline { 2 - 5 } & Equity & Inequity & Equity & Inequity \\
\hline Judge & $0.30(1.21)$ & $0.25(1.28)$ & $0.34(1.26)$ & $0.13(1.01)$ \\
Ethical to under-report & $-0.73(0.94)$ & $-0.66(1.03)$ & $-0.64(0.99)$ & $-0.40(0.98)$ \\
Anchoring behavior on beliefs & $2.40(0.66)$ & $2.25(0.74)$ & $2.34(0.71)$ & $2.13(0.71)$ \\
Fairness of earnings & $0.84(0.87)$ & $-0.06(1.00)$ & $1.09(0.88)$ & $-0.50(1.13)$ \\
\hline \hline
\end{tabular}

Notes: Response scales: "Judge": -2 - very unethical, -1 - unethical, 0 - neither unethical, nor ethical, 1 - ethical, 2 - very ethical. "Ethical to ...": -2 - very much disagree, -1 - disagree, 0 - neither agree nor disagree, 1 - agree, 2 - very much agree. "Anchoring ...": 1 - not at all, 2 - somewhat, 3 - very much. "Fairness ...": -2 - very unfair, -1 - unfair, 0 - neither unfair nor fair, 1 - fair, 2 - very fair. 